\title{
Mekanisme Pelaksanaan Layanan Lumpur Tinja Terjadwal (LLTT) Studi pada Dinas Pekerjaan Umum dan Penataan Ruang (PUPR) Kota Kendari
}

\author{
Azwar'; Suriyani BB ${ }^{2 ;}$ Muh. Yusuf ${ }^{3}$ \\ 1,2,3 Universitas Halu Oleo, azwarhidayat42443@gmail.com
}

\begin{abstract}
Abstrak
Tujuan penelitian ini adalah untuk mengatahui mekanisme pelaksanaan layanan lumpur tinja terjadwal dan faktor-faktor yang mempengaruhi mekanisme pelaksanaan layanan lumpur tinja terjadwal. Penelitian ini menggunakan metode deskriptif dengan pendekatan kualitatif. Penelitian ini dilaksanakan pada Dinas Pekerjaan Umum Dan Penataan Ruang Kota Kendari. Informan dalam penelitian ini yaitu, Kepala Dinas UPTD, Bendahara Penerimaan, dan Masyarakat. Teknik pengumpulan data terdiri dari Penelitian Kepustakaan terdiri dari makalah ataupun skripsi terdahulu, referensi buku, dan internet searching dan Penelitian Lapangan terdiri dari observasi, wawancara, dan dokumentasi. Teknik analisis data bersifat deskriptif kualitatif. Hasil penelitian menunjukan bahwa masih banyaknya masyarakat yang memiliki tangki septic tidak standar, sehingga akan mengakibatkan pola kesehatan masyarakat terganggu, dan kemudian masih kurang akan kesadaran member program Layanan Lumpur Tinja Terjadwal dalam pembayaran iuran. Oleh sebab itu maka dengan adanya program Layanan Lumpur Tinja Terjadwal dapat membantu meminimalisir dampak tersebut. Konsep mekanisme pelaksanaan layanan lumpur tinja terjadwal sebagai bentuk program pemerintah dengan melihat faktor penghambat mekanisme pelaksanaan Layanan Lumpur Tinja Terjadwal merupakan salah satu fenomena yang menjadi tugas dan tanggung jawab bersama baik itu antar pemerintah maupun masyarakat.
\end{abstract}

Kata kunci : Layanan Lumpur Tinja Terjadwal, Mekanisme, Pelaksanaan.

\begin{abstract}
The purpose of this study is to know the mechanism of scheduled fecal sludge service implementation and factors affecting the mechanism of scheduled fecal sludge service implementation. This study uses a descriptive method with a qualitative approach.This research was conducted at the Public Works and Spatial Planning Office of Kendari City. Informants in this study, namely, the Head of the UPTD Office, the Treasurer of Admissions, and community. Data collection techniques consist of library research consisting of previous papers or theses, book references, and internet searching and field research consisting of observations, interviews, and documentation. The data analysis technique is descriptive qualitative. The results showed that there are still many people who have non-standard septic tanks, which will result in disturbed public health patterns, and then there is still less awareness of the members of the Scheduled Feces Sludge Service program in paying contributions. therefore, with the Scheduled Feces Sludge Service program can help minimize these impacts. The concept of scheduled sludge service implementation mechanism as a form of government program be a shared duty and responsibility between governments and the community.
\end{abstract}

Keywords : Scheduled Fecal Sludge Services, Mechanism, Implementation. 


\section{Pendahuluan}

Peraturan Daerah (Perda) Kota Kendari No 3 tahun 2016 tentang pengelolaan air limbah domestic, dan Instruksi Walikota Kendari Nomor 2 tahun 2018 Tentang Layanan Penyedotan Lumpur Tinja Terjadwal dan Penggunaan Tangki Septik Sesuai Standar, yang ditujukan pada kantor atau instansi seperti puskesmas, dinas, perusahaan, perhotelan, restoran, warung makan, dan individu, merupakan salah satu prioritas pemerintah dalam penyediaan prasarana dan sarana air limbah untuk mencapai target pencapaian universal akses sanitasi. Yang dimaksud pengelolaan air limbah domestik dalam penelitian ini yaitu lumpur tinja, yang di tujukan kepada individual saja, seperti masyarakat ASN.

Layanan Lumpur Tinja Terjadwal (LLTT) merupakan program Kota Kendari berbasis lingkungan dengan penerapan septic tank standard yang diresmikan oleh Walikota Kendari, pada tanggal 15 Agustus 2018 di Rumah Jabatan Wakil Walikota Kendari. Mekanisme program Layanan Lumpur Tinja Terjadwal (LLTT) menjadi hal yang begitu penting karena dapat mempengaruhi peningkatan kualitas pelayanan publik kepada masyarakat khususnya Kota Kendari. Tidak hanya berpengaruh terhadap kualitas pelayanan, tetapi juga berdampak terhadap peningkatan prekonomian daerah.

Program LLTT merupakan layanan penyedotan lumpur tinja dari tangki septik secara berkala dan terjadwal yang diselenggarakan sesuai kesepakatan dengan pelanggan atau ketentuan yang berlaku. Pelaksana tugas (Plt) Wali Kota Kendari, Sulkarnain Kadir mengatakan, program LLTT tersebut sangat sesuai dengan visi dan misi Pemkot Kendari untuk menjadikan Kota Kendari sebagai kota layak huni yang berbasis ekologi dan untuk membuat program tersebut berjalan maka tahap awal penerapan Program LLTT akan dilakukan di lingkup ASN Pemda Kota Kendari terlebih dahulu. Sekitar 40 persen ASN Kota Kendari sudah terdaftar sebagai peserta pengurasan tinja terjadwal dan di targetkan bisa diterapkan kepada masyarakat.

Implementasi program layanan lumpur tinja dimulai dari persiapan agar lumpur tinja terjadwal dapat terselenggara dengan baik di suatu kota. Mulai hal-hal terkait aspek regulasi, kelembagaan, infrastruktur sampai ke pengelolaan 
pelanggan. Banyak pihak perlu di libatkan. Tidak hanya lembaga pengelola operasi LLTT, tetapi juga instansi-instansi pemerintah yang memastikan masyarakat untuk menggunakan tanki septic yang benar dan melakukan penyedotan berkala. Didalam program ini tentunya memiliki kendala yang dilaksanakan oleh pihak dinas misalkan pada skema tarif yang biaya angsuranya perbulan tidak berjalan baik.dan masih kurangnya masyarakat dan OPD yang menggunakan tangki septic standar.

Berdasarkan uraian di atas maka penelitian ini bertujuan untuk mengatahui mekanisme pelaksanaan layanan lumpur tinja terjadwal dan faktor-faktor yang mempengaruhi mekanisme pelaksanaan layanan lumpur tinja terjadwal.

\section{Metode}

Lokasi penelitian ini adalah pada Dinas Pekerjaan Umum Dan Penataan Ruang PUPR Kota Kendari dengan pertimbangan bahwa sebagai ibu kota Propinsi Sulawesi Tenggara dengan perkembangan yang ada ternyata tidak bisa juga terlepas dari masyarakatnya yang kurang begitu memperhatikan kesehatan. Alasan memilih lokasi penelitian ini, karna dinas inilah yang melaksanakan program LLTT sehingga disini yang pastinya banyak data yang saya butuhkan. Adapun alasan peneliti untuk melakukan penelitian yaitu untuk mengetahui Bagaimana Mekanisme Pelaksanaan Layanan Lumpur Tinja Terjadwal LLTT Pada Dinas PUPR Kota Kendari. Jenis penelitian ini bersifat kualitatif, yang memberikan gambaran tentang Implementasi Program Layanan Lumpur Tinja Terjadwal (LLTT), dan Apa Saja Faktor-faktor Yang Mempengaruhi Mekanisme Pelaksanaan Program Layanan Lumpur Tinja Terjadwal ( LLTT ) kota kendari. Tipe penelitian yang digunakan adalah tipe kualitatif yaitu penelitian yang tujuan utamanya adalah untuk memperoleh wawasan tentang topik tertentu. Teknik yang digunakan dalam penelitian kualitatif pada umumnya yaitu metode wawancara dan observasi. Informan dalam penelitian ini terdiri dari 6 informan yaitu diantaranya, Kepala Dinas LLTT, Bendahara Penerimaan, Masyarakat ASN sejumlah 3 orang. Dalam pelaksanaan penelitian ini, penulis menggunakan teknik analisis data bersifat deskriptif. Analisis ini akan mendeskripsikan hasil penelitian berdasarkan informasi yang diperolaeh baik dari hasil obser vasi/survey maupun wawancara. 


\section{Hasil dan Pembahasan}

\section{Mekanisme/Alur Pelaksanaan LLTT}

Mekanisme merupakan tata cara yang disusun sedemikian rupa sehingga tidak menimbulkan benturan dalam pelaksanaannya. Sebelum membahas mekanisme Pelaksanaan Layanan Lumpur Tinja Terjadwal, terlebih dahulu peneliti akan membahas mengenai LLTT, dan siapa saja yang terlibat dalam program ini. Layanan Lumpur Tinja Terjadwal (LLTT) adalah suatu mekanisme pelayanan penyedotan lumpur tinja yang dilakukan secara periodik atau terjadwal yang diterapkan pada sistem pengelolaan air limbah setempat, yang kemudian diolah pada instalasi yang ditetapkan serta terkait dengan metode pembayaran yang telah ditetapkan. program (LLTT) merupakan program yang sangat sesuai dengan visi dan misi pemkot Kendari untuk menjadikan kota layak huni yang berbasis ekologi dan untuk membuat program tersebut berjalan maka tahap awal menerapkan program LLTT akan dilakukan di dalam lingkup ASN pemkot terlebih dahulu.

Pelaksanaan program layanan lumpur tinja terjadwal pada umumnya adalah program pemerintah daerah Kota Kendari sebagai wujud penerapan dalam UU No 25 Tahun 2004 yang tertuang pada RPJMN tentang pengelolaan kualitas air dan pengendalian pencemaran air yang menjadi salah satu prioritas pemerintah Indonesia. Program ini pada dasarnya yaitu berbasis lingkungan dengan penerapan tanki septic tank standard yang digunakan oleh pemerintah dan masyarakat Kota Kendari. banyak masyarakat menggunaaan tanki septic tank tidak standar sehingga mengakibatkan kesehatan dan lingkungan tidak sehat.

Program LLTT yaitu program yang berbasis ramah lingkungan dengan melihat berbagai jenis akibatnya maka terkhusus program ini merupakan langkah pemerintah dalam mencari solusi agar bagaimana konsep lumpur tinja tidak mempengaruhi kesehatan masyarakat tetapi juga perlu diketahui bahwa untuk masuk program ini harus mengikuti mekanisme yang telah ditetapkan pemerintah" (Aridan, 2019).

Program ini dilakukan secara berkala dan terjadwal yang tentunya masyarakat dan OPD harus mengikuti prosedur pendaftaran dalam mengikuti 
program tersebut agar paham tentang pelaksanaan program LLTT. Ada beberapa prosedur dalam mekanisme pelaksanaan LLTT yakni :

\section{a. Melakukan Pendaftaran Berbasis Online}

LLTT harus didukung oleh managemen information system ( MIS) yang mampu mengendalikan urusan pelanggan, urusan tekhnis dan urusan keuangan secara terintegrasi. MIS LLTT akan memastikan seluruh pelanggan yang terdaftar dapat menerima pelayanan sedot tinja sesuai dengan jadwal yang ditentukan.

Sesuai dengan hasil wawancara informan Kepala UPTD Kota Kendari bahwa yang terpenting adalah melakukan pendaftaran lewat WEB (Http://12t2kotakendari.blogspot.com) terlebih dahulu kemudian harus memenuhi syarat mulai dari pendaftaran, dari tanggal berapa dan bulan berapa dia mengikuti kegiatan LLTT. Mengenai berkas, tidak ada berkas yang harus di kumpulkan, tetapi hanyalah mengisi formulir pada laman web yang telah di sediakan, seperti : alamat, kawasan rumahan, tangki septic, jarak tanki dari jalan poros berapa meter, karena jangan sampai mereka yang sudah mendaftar kemudian rumahnya jauh masuk kedalam lorong dan mobil truk tinja tidak bisa melewati lorong tersebut, sehinnga harus diketahui berapa jarak tanki septic dari jalan poros. Sedangkan panjang selang yang digunakan oleh truk pengankut tinja tersebut juga terbatas. Yang pada intinya selagi selang dapat menempuh jarak yang cukup pasti masih bisa mengikuti kegiatan tersebut. Dan selama ini mengenai kendala yang di temukan selaku pemerintah, tidak ada tapi bagi customer itu sendiri, biasanya mereka yang baru memilki tampat tinggal, terkadang tidak mengetahui posisi tangki septic yang ada pada rumah tersebut dan otomatis jarak akan menjadi perhitungan untuk berjalannya proses penyedotan.(Aridan, 2019)

Hal senada juga diungkapkan Marwah (2019) bahwa dalam pelaksanaan program LLTT pemerintah daerah telah menyediakan web site berbasis online bagi OPD dan untuk masyarakat juga ada yang ksusus kategori umum. untuk mengikuti program ini, harus berdasarkan prosedur/persyaratan yang telah ditentukan. Ini merupakan langkah awal dalam memenuhi salah satu syarat. Sehingga bisa terdaftar dalam program LLTT. Dalam pendaftaran LLTT, tidak ada kesulitan sama sekali karna langsung login ke dalam website yang telah di sediakan, 
dan juga adanya pihak instansi yang mendaftarkan kami para ASN sehingga tidak ada kesulitan dalam proses pendaftaran. Agustina (2019)

Berdasarkan hasil wawancara di atas dapat disimpulkan bahwa prosedur layanan lumpur tinja terjadwal harus diawali dengan pendaftaran melalui Web Http://12t2kotakendari.blogspot.com) yang telah disediakan oleh pemerintah kota dengan berdasarkan kelayakan syarat dimulai dari alamat,jarak rumah,memiliki tangki septic yang jarak tempuhnya dari jalan raya tidak kurang dan lebih rata' 5070 M.sesuai dengan jarak selang pada tangki truk yang telah disediakan. Kemudian dari hasil wawancara oleh masyarakat, bahwa dalam proses pendaftaran, tidak ada kesulitan sama sekali karna di sarankan langsung login ke website dan juga ada pihak kantor yang bersedia mendaftarkan.

\section{b. Sistem Pembayaran Angsuran Bulanan}

Angsuran merupakan iuran yang harus dibayar sesuai dengan waktu yang telah di sepakati oleh pihak tertentu, baik itu dalam jangka waktu perminggu, perbulan, maupun pertahun, sesuai dengan kesanggupan pelanggan. Dalam pelaksanaan layanan lumpur tinja terjadwal, mengenai Sistem pembayaran yaitu sistem yang mencakup seperangkat aturan, lembaga, dan mekanisme yang dipakai untuk melaksanakan pemindahan dana guna memenuhi suatu kewajiban yang timbul dari suatu kegiatan penyedotan LLTT. Komponen-komponen dalam sistem pembayaran ialah alat pembayaran melalui perorangan dan lembaga terlibat dalam menyelenggarakan system pembayaran.dalam hal ini lembaga yang dimaksud adalah Bank dan lembaga keuangan selain bank.

Pelaksanaan program sanitasi layanan lumpur tinja Kota Kendari di tahun 2018 Siti Marwah selaku bendahara penerimaan biaya angsuran mengatakan bahwa, jadwal penyedotan dilakukan secara berkala tiap 2 tahun sampai 5 tahun sekali sedot. Sehingga jajaran ASN dapat melakukan cicilan selama 2 tahun untuk membayar 1 kali penyedotan. Tarif penyedotan sebesar Rp 400.000,00 itupun perlu dibayarkan sebesar Rp 16,667,-/Bulan,dan untuk ASN yang tinggal diluar kota tarif retribusi jasa LLTT satu juta.Tetapi khusus untuk pelayanan umum untuk masyarakat dibayar 1 kali secara langsung dengan nilai 400.000, dan bagi yang mau 
melakukan penyedotan secara mendadak, bisa langsung di layani dengan menghubungi kami. Adapun kendala yang dihadapi oleh pemerintah yaitu bahwa sebagian ASN sudah melakukan pendaftaran tetapi tidak melaksanakan pembayaran biaya retribusi jasa LLTT Karna sebagian ASN tinggal diluar kota dan ada juga yang masih tinggal dikost-kosan. (Marwah, 2019)

Berdasarkan keterangan informan di atas bahwa biaya angsuran yang berlaku khusus bagi para ASN, dapat dilakukan malalui cicilan dengan potongan gaji sebesar 16,667 perbulannya apabila mau melunasi biaya sedotan tinja secara langsung itu dikenakan tariff sebanyak 400 dan kalau ASN diluar dari Kota Kendari dikenakan biaya sebesar 1 juta. Dan sebagian banyak masyarakat tidak merasa kesulitan terhadap biaya retribusi tersebut.

\section{c. Memiliki Tangki Septic}

Septic tank merupakan tangki yang berwujud bak atau wadah yang bersekat sehingga terbagi dalam beberapa ruang dan terkubur didalam tanah. Secara umum, septic tank berfungsi sebagai pembuangan kotoran, tinja, dan sejenisya yang tidak boleh di salurkan kedalam saluran pembuangan umum, dengan alasan kesehatan serta faktor kebersihan lingkungan. Program LLTT ditujukan bagi rumah tangga yang memiliki tangki septic (septic tank) dan akan di sedot secara terjadwal dalam kurun waktu 2 tahun sekali penyedotan untuk tangki septic yang tidak kedap dan sekali dalam 3 tahun untuk tangki septic yang kedap karena selama ini tangki septic (septic tank) dirumah tangga baru akan disedot atau dikuras kalau sudah penuh atau mampet.

Perlunya pengadaan pelaksanaan penyedotan lumpur tinja sangatlah penting karna dapat mencemari tanah terutama pada masyarakat yang menggunakan sumur galian, akan menyebabkan merembesnya air tinja pada sumur tersebut sehingga dapat mmenyebabkan pencemaran lingkungan. Ini kita masih berbicara tentang tinja belum lagi sampah-sampah yang berada pada warung makan, mereka membuang lewat saluran goot, oleh karna itu sangat lah perlu adanya penyedotan tangki septic. Kemudian untuk tangki septic itu dibagi menjadi dua yang kedap dan tidak kedap yaitu tidak memiliki dinding dasar pemisah antara 
tanah dengan semen sehingga dapat beperngaruh terhadap lingkungan. ( Aridan, 2019)

Jadi, dapat disimpulkan bahwa keharusan memiliki tangki septic adalah untuk bagaimana operator penyuluhan tinja mudah dalam melakukan penyedotan tinja dan itu merupakan hal yang penting didalam pelaksanaan program tersebut.

\section{d. Memiliki Akses Penyedotan Tangki Septic}

Akses penyedotan merupakan jalur menuju tangki septik yang ingin dilakukan penyedotan, karena akses ini ialah salah satu syarat dalam mekanisme pelaksanaan LLTT. Salah satu masalah yang sering terjadi pada masyarakat ASN adalah jauhnya akses penyedotan tangki septic, dan juga sempitnya akses jalan yang akan di lalui mobil truk tangki, sehingga dapat menghambat pelaksanaan LLTT.

Idealnya, setiap tangki septic tank selain akses jalan. Harus juga memiliki akses penyedotan yang dinamakan lubang pipa saluran. Apabila setiap tangki tidak memiliki lubang penyedotam maka akan sulit untuk dilakukannya penyedotan, sehingga akses ini perlu dalam mekanisme Layanan Lumpur Tinja Terjadwal. Tapi kebanyakan masyarakat kota kendari yang memiliki bak atau penampungan limbah lumpur tinja. tetapi tidak mamiliki lubang penyedotan hanya memiliki pipa sebagai tempat pembuangan gaz lumpur.

Dalam akses pelaksanaan penyedotan LLTT itu haru memiliki akses penyedotan atau lubang sedot pada tangki septic. Kemudian akses jalan menuju tangki septic/rumah masyarakat. Dari hasil wawancara oleh informan mengenai akses jalan yaitu "Akses jalan juga perlu kita perhatikan karna mobil ini kan tidak bisa lewat dalam gang gang kecil sehingga dalam pendaftaran ini perlu di seleksi lagi apakah tempat tersebut bisa di jangkau oleh kendaraan. Walaupun tidak bisa di akses oleh kendaraan paling tidak selangnya sampai kedalam karnah jarak selang yang digunakan 50-70 $\mathrm{M}$ oleh truk pengankut tinja tersebut terbatas yang intinya selagi selang dapat menempuh jarak yang cukup pasti masih bisa mengikuti kegiatan tersebut". ( Aridan, 2019)

Berdasarkan hasil wawancara diatas peneliti dapat menyimpulkan bahwa akses penyedotan tanki septic seperti turk pengankut, akses jalan yang tidak jauh 
yang memungkinkan jarak pipa penyedotan dapat dicapai dan harus memiliki tangki septic yang standard dilihat dari kedap atau tidak kedapannya.

\section{Faktor-Faktor yang Mempengaruhi Mekanisme Pelaksanaan LLTT}

\section{a. Faktor Kesadaran}

Banyak masyarakat yang tidak menyadari bahwa tanki septik yang standar yaitu tanki yang tidak kedap dalam artian tidak bocor atau tenmbus air. Sebagaimana dalam wawancara informan "kami tidak tahu bahwa tanki septic yang kami gunakan ini standard atau tidak, karna kami juga membeli rumah yang memang sudah ada tangki septiknya, dan tidak mungkin juga kita periksa tangki tersebut, jadi kami mengisi data yang standard saja" (Rachel, 2019). Dapat di tarik kesimpulan bahwa sebagian masyarakat tidak sadar bahwa tangki yang digunakan itu standar atau tidak, sehingga dapat mempengaruhi lingkungan sekitar mereka

\section{b. Faktor Aturan}

Aturan merupakan salah satu faktor yang mempengaruhi mekanisme pelaksanaan LLTT seperti angsuran yang harus di bayar jika inigin melakukan penyedotan. Dalam pembayaran biaya penyedotan, tentunya ada beberapa model angsuran yang sudah diatur dalam Perda Kota Kendari Nomor 2 Tahun 2012 Tentang Jasa Retribusi Jasa yaitu 400 ribu dan 1 juta/sekali sedot tetapi yang menjadi kendala yaitu sebagian masyarakat tidak mau membayar walaupun sudah melakukan pendaftaran, dikarenakan mereka tiggal di koskosan. Dan ada juga yang tinggal di luar kota sehingga biaya yang harus di bayar sebesar 1 juta. Sehingga dapat mempengaruhi mekanisme pelaksanaan”. ( Marwa, 2019)

\section{c. Faktor Organisasi}

Faktor organisasi dalam mekanisme pelaksanaan LLTT sangatlah penting, karna untuk melaksanakan LLTT harus banyak lembaga yang terlibat didalamnya, guna unutuk menyampaikan kepada semua aparat yang ada dalam lembaga tersebut. Dimana program LLTT sangat diwajibkan untuk semua instansi sehingga kerjasama sangat diperlukan. Sebagimana yang di jelsakan oleh informan bahwa “dalam pelaksanaan LLTT merupakan sebuah program yang mana program ini di wajibkan untuk semua instansi, jadi kerja sama untuk tiap-tiap lembaga itu sangat 
diperlukan agar setiap pemimpin lembga bisa memberitahukan para aparatnya untuk mengikuti program LLTT tersebut (Aridan, 2019). Namun demikian masih banyak diantara lembaga-lembaga tersebut kurang bertartisipasi terhadap program ini, karna banyak diantara mereka para pelanggan (masyakat ASN) tidak mengetahui adanya program LLTT ini, padahal kami sudah menyurati lembaga tersebut tetapi masi banyak masyarakat ASN yang tidak mengetahui apa itu layanan lumpur tinja terjadwal. (Marwa, 2019)

\section{d. Faktor Keterampilan Petugas}

Keterampilan petugas sangat diperlukan pada saat akan melaksanakan penyedotan karna tidak semua pelanggan mengetahui posisi tangki septicnya. Sebagian masyarakat tidak mengtahui posisi tangki septic yang ada pada rumah mereka, karna banyak masyarakat yang memiliki tempat tinggal baru dan mereka tidak mengetahui mengenai posisinya sehingga akan menghambat proses penyedotan. Disinilah peran para petugas untuk mempercepat proses penyedotan. ( Aridan, 2019)

\section{e. Faktor Sarana dan Prasarana}

Sarana dan prasara sangat penting dalam proses pelaksanaan LLTT khususnya akses jalan dan transportasi.dalam proses penyedotan. Mengenai sarana dan prasarana akan membahas 2 aspek dalam LLTT ini yaitu akses jalan dan transportasi. akses jalan dalam LLTT itu harus di perhatikan karna apabila rumahn customer tidak bisa dilalui truk tangki maka terpaksa harus menggunakan selang untuk menjangkau tanki septik. Sedangkan panjang selang hanya 50-70 M. Apabila melebihi panjang selang maka otomatis akan menghambat proses penyedotan. (Aridan, 2019)

\section{Kesimpulan}

Berdasarkan hasil pembahasan tentang mekanisme Pelaksanaan Layanan Lumpur Tinja Terjadwal (LLTT). Dengan melihat mekanismenya program pelaksanaan LLTT yang di awali dengan langkah pertama, melakukan pendaftaran melalui Web yang telah di sediaka oleh dinas PUPR. Kedua, bersedia membayar 
angsuran bulanan. Ketiga, memiliki tangki septic. Keempat, memiliki akses penyedotan tangki septic. Sebagian masyarakat memiliki akses penyedotan yang tidak dapat di jangkau oleh selang truk LLTT. Kedua sebagian masyarakata yang sudah mendaftar tidak mengetahui/tidak memiliki lubang penyedotan pada tangki yang digunakan. Ketiga sebagian masyarakat yang sudah mendaftar tetapi tidak melakukan pembayaran angsuran bulanan.

\section{Referensi}

Azwar, Azrul, (1995). Pengantar Kesehatan Lingkungan, PT. Rineka Cipta. Jakarta Bagus. (1996). Kamus Filsafat. Jakarta: Gramedia

Kurniawan, Agung. (2013), Transformasi Pelayanan Publik, yogyakarta

Moenir. (2013). Manajemen Pelayanan Umum Di Indonesia. Jakarta: bumi aksara. Hardiyansyah. (2011). Kualitas Pelayanan Publik. Yogyakarta: gava media.

Miles, M. B. \& Huberman, M. (1992). Analisis Data Kualitatif. Jakarta: UI pres

Nawawi. (2001). Metodologi Penelitian Bidang Sosial. penerbit : gajah mada Yogyakarta

Nurdin, U. (2002). Konteks Implementasi Berbasis Kurikulum. Bandung: CV. Sinar baru.

Poerwadarmita. (2003). Kamus Umum Bahasa Iundonesia. Jakarta : balai pustaka. Sinambela. (2013). Reformasi pelayanan publik, teori kebijakan dan implementasi. Jakarta : PT Bumi Aksara.

Sulistyastuti. (2007). Metode Penelitian Kuantitatif. Jakarta: gava media Santosa, panji. (2009). Administrasi Publik : teori dan aplikasi good Governance. Jakarta : gramedia

Soekanto, Soerjono, (1982). Pokok-Pokok Sosiologi Hukum. Jakarta : PT.Raja Grafindo Persada

Soekanto, Soerjono, (1983). Pengantar Penelitian Hukum. UI Pres. Jakarta.

Thoha, M. (1991). Perspektif Perilaku Birokrasi. Jakarta: Rajawali Pres

Walikota Kendari. (2016). Perda Kota Kendari No 3 Tahun 2016 Tentang Pengelolaan Air Limbah Domestik 


\section{Hasil Wawancara}

Aridan. (2019). Dinas Pekerjaan Umum Dan Penataan Ruang (PUPR).12

November 2019

Agustina. (2019). Kendari. 25 November 2019

Arif. (2019).Kendari. 25 November 2019

Marwa. (2019). Dinas Pekerjaan Umum Dan Penataan Ruang (PUPR).14 November 2019

Rachel. (2019). Kendari. 25.November 2019 